\title{
USO DE TECNOLOGIA INFORMAÇÃO E COMUNICAÇÃO (TIC's) NAS AULAS DE QUÍMICA NO CONTEÚDO DE ISOMERIA GEOMÉTRICA (ESTEREOISOMERIA)
}

\section{USE OF INFORMATION AND COMMUNICATION TECHNOLOGY (ICT) IN CHEMISTRY CLASSES IN THE CONTENT OF GEOMETRIC ISOMERIA (STEREOISOMERY)}

\author{
Ayrton Matheus da Silva Nascimento ${ }^{1}$; Natália Kelly da Silva Araújo ${ }^{2}$; Jaqueline Costa da \\ Silva Lima ${ }^{3}$; Patrícia Hander de Lucena Neri ${ }^{4}$; Kilma da Silva Lima Viana ${ }^{5}$
}

\begin{abstract}
RESUMO
A utilização de aplicativo (APP) no ensino de química é um desafio, pois necessita de diversos aparatos tecnológicos e didáticos, como um dispositivo móvel, smartphone, assim impulsiona mudanças na forma como os sujeitos se relacionam com a informação e produzem o conhecimento. O uso do TIC's como recurso no processo de educação, deve servir de inovação pedagógica, porém para que isso ocorra, é fundamental que o professor tenha conhecimento sobre as possibilidades do recurso tecnológico, para utilizá-lo como instrumento de aprendizagem. Esta pesquisa apresenta uma experiência com APP, intitulado "Isomère Z/E" utilizando como aparato metodológico o CEK apoiado George Kelly (1963). Este APP é direcionado para alunos do Ensino Médio ( $3^{\circ}$ Ano), na temática de Isomeria Geométrica ou Estereoisomeria, tratando sobre os tipos de isomeria (cis ou trans) e (E ou Z), onde deve identificar e nomear as estruturas carbônicas. Esta ferramenta tecnológico encontra-se no Playstore na interface de M. Chardine (2014), esta experiência foi realizada numa turma de $3^{\circ}$ ano do Ensino Médio, na qual é parceira do programa, na cidade de Recife - PE. Os resultados atingidos foram empregado com o CEK, na qual distingui na antecipação alguns erros conceituais sobre as classificações das isomeria geométrica como (cis ou trans) e (E ou Z), já no investimento a explicação do conteúdo cogitado em cima dos números de dificuldades, no foi necessário ser direcionado pelas regras do uso do APP, na confirmação ou desconfirmação e pode-se percebe que a quantidade de erros é equivalente a $16 \%$, onde houve uma redução de $52 \%$, e os de erros chegou a $84 \%$, mostrando-se assim que o uso de recurso didático em sala de aula, contribui para o processo de formação e construção dos conceitos químicos, e na revisão construtiva foi concentrizado uma conversa sobre a utilização de tecnologias no ensino de química, os benefícios e os malefícios do seu uso, e foi perceptível que o uso de tecnologia na temática estereoisomeria facilitou a compreensão dos conceitos químicos.
\end{abstract}

Palavras-Chave: ensino, aprendizagem de conceitos, APP

\begin{abstract} didactic devices, such as a mobile device, a smartphone, thus impelling changes in the way

\footnotetext{
${ }^{1}$ Especialista em Ensino de Química, UCAM - Prominas, ayrthon.matheus@ gmail.com

${ }^{2}$ Graduanda em Química, IFPE - Campus Vitória, nataliakellybs@ gmail.com

${ }^{3}$ Especialista em Proficiência em Libras e Pedagogia, UFPE, jackeline.libras@gmail.com

${ }^{4}$ Licenciada em Pedagogia, UFPE, patylucena80@ hotmail.com

${ }^{5}$ Doutora em Ensino de Ciências, IFPE - Campus Vitória, kilma.viana71@gmail.com
}

The use of APP in chemistry teaching is a challenge, since it requires several technological and subjects relate to information and produce knowledge. The use of ICT as a resource in the education process should be a pedagogical innovation, but for this to happen, it is essential that the teacher is aware of the possibilities of the technological resource, to use it as a learning tool. This research presents an experience with APP, entitled "Isomère Z / E" using as a methodological apparatus CEK supported George Kelly (1963). This APP is aimed at high 
school students (3rd year), in the subject of Geometric Isomeria or Stereoisomeria, dealing with the types of isomeria (cis or trans) and (E or Z), where it must identify and name the carbonic structures. This technological tool is found in Playstore at the interface of M. Chardine (2014), this experience was carried out in a 3rd year high school class, in which she is a partner of the program, in the city of Recife - PE. The results obtained were used with the CEK, in which I distinguished in the anticipation some conceptual errors about the classifications of the geometric isomeria as (cis or trans) and (E or Z), already in the investment the explanation of the content considered on top of the numbers of difficulties, it was not necessary to be guided by the rules of the use of the APP in the confirmation or disconfirmation and it can be perceived that the number of errors is equivalent to $16 \%$, where there was a $52 \%$ reduction, and the error rate reached $84 \%$ showing that the use of didactic resources in the classroom contributes to the process of formation and construction of the chemical concepts, and in the constructive review was concentrated a conversation about the use of technologies in the teaching of chemistry, benefits and harm of its use, and it was perceptible that the use of technology in the thematic stereoisomeria facilitated the understanding of the chemical concepts.

Keywords: teaching, learning concepts, APP.

\section{INTRODUÇÃO}

Nos últimos anos, a inclusão digital nas escolas caracteriza uma nova prática por meio do alargamento da rede de modernidades na tecnologia, proporcionando novas formas de trabalhar os conteúdos curriculares e aumentando a interação de alunos e professores com diferentes linguagens. Os recursos tecnológicos são as ferramentas que contribuem ao desenvolvimento social, econômico, cultural e intelectual.

As novas tecnologias apresenta uma grande inovação para a educação, pois os professores podem utilizá-la como recurso pedagógico para facilitar o processo de ensinoaprendizagem. Atualmente o uso das tecnologias da informação e comunicação móveis e sem fios, como os dispositivos móveis (smartphones), é bastante comum, e quando conectados à internet tem acesso a uma variedade de aplicativos gratuitos (BENTO, 2013).

O uso das Tecnologias de Comunicação e Informação (TIC's) pelos professores, como recurso no processo de educação, deve servir de inovação pedagógica, mas para que isso ocorra, é fundamental que o professor tenha conhecimento sobre as possibilidades do recurso tecnológico, para utilizá-lo como instrumento de aprendizagem. Mas o que nos deparamos hoje em dia é com as dificuldades encontradas para que as TIC mantenha uma união com a sala de aula, as inovações são inúmeras, porém o professor deve buscar estas inovações e praticá-las no seu cotidiano. Mesmo com todas as vantagens que as TIC podem proporcionar à relação didático-pedagógica, parece haver um certo descompasso presente na realidade vivenciada por professores e alunos nas escolas públicas para a sua inserção nas práticas escolares. Isso porque "ainda existem muitas barreiras a serem superadas para a integração efetiva das TIC aos processos pedagógicos, que vão além das dificuldades associadas a questões de infraestrutura 
das TIC nas escolas.” (BARBOSA, 2014, p.28).

Assim sendo, há necessidade que os professores tomem ciência de que podem e devem ocorrer mudanças nas práticas pedagógicas de forma a superarem possíveis obstáculos que a eles se apresentam na utilização destes instrumentos, seja para o planejamento de suas aulas, bem como no trabalho com os alunos para o desenvolvimento dos conteúdos das diversas disciplinas escolares, essa é uma tarefa árdua e de imensa dificuldade para nossa realidade, principalmente no que tange o ensino público, mas que auxilia significativamente para a aprendizagem dos estudantes, como afirma Sartori (2014):

\footnotetext{
As TICs podem servir de meio para se ampliar os saberes e para se criar novas formas de aprender e ensinar. É inegável que seu uso vem ampliando possibilidades comunicativas e educativas. SARTORI (2014).
}

Os diferentes estudos compartilham um elemento em comum: reconhecer a necessidade dos docentes, gestores e estudantes incorporarem mais o uso das TICs, e concluem pela necessidade de maior inserção dos recursos digitais nos contextos de ensino e aprendizagem que ajudem a todos os atores de forma cotidiana e significativa SARRAMON (2004). Acrescentamos aqui que a inserção e uso crítico a partir da atuação pedagógica são excessivamente importantes e necessários compreender a lógica e como se faz uso desta para que haja o ensino e aprendizagem com sucesso por parte dos educandos.

Este artigo apresenta um resultado de uma vivência com uma de 37 (trinta e sete) do terceiro ano do ensino médio, com o intuito de mostrar os benefícios que as tecnologias apresentam numa aula num conteúdo de Isomeria Geométrica (ou Estereoisomeria).

\section{FUNDAMENTAÇÃO TEÓRICA}

Desde a década de 1990, quando a internet se popularizou, até os dias atuais, passamos a estar cada vez mais conectados. A cada minuto que passa, "novas pessoas acedem à internet, novos computadores são interconectados, novas informações são introduzidas na rede. Quanto mais o ciberespaço se amplia, mais este se torna "universal", e menos o mundo informacional se torna totalizável” (LÉVY, 2005, p. 111).

É nítido que cada vez mais estamos nos tornando mais criativos, as Tecnologias de Comunicação e Informação (TIC's) cada vez mais ocupa mais espaço, hoje em dia invadem nossas casas, a reuniões de família e os espaços de lazer, e não são deferentes no ambiente escolar, os adolescentes dessa nova geração vem se mostrando cada vez, mas interessados pelas tecnologias e entrando nesse mundo de comunicação e informação. As pessoas passaram a prover de fontes de informação por meio de uma internet cada vez mais democratizada, trazendo consigo novas responsabilidades. Todavia, "o que chamamos de modernidade é o resultado do 
lento processo iniciado no século XVII, e caracterizado pela abertura progressiva das fronteiras, de todas as fronteiras, começando pelas mentais e cultural” (WOLTON, 2003, p. 49).

Nesta visão, educar nesta era digital, por meio das TIC's, pressupõe uma atitude por parte dos docentes distinta da convencional. Para isso, torna-se fundamental a motivação. Mas como sensibilizar e estimular professores e diretores para o uso das tecnologias de informação e comunicação? Qual a importância delas em sala de aula? A compreensão e aplicação das tecnologias da informação e comunicação TIC's em sala de aula constituem-se em passos importantíssimos que tem aproximado professores para um mundo midiático, propiciando maior dinâmica e interação por parte de educandos e educadores em sala de aula. Por vezes, a preocupação central do professor está voltada para o ensino, como um sinônimo de transmissão de conteúdo.

Nestes princípios, Paulo Freire (1994) já apregoava que o professor não deve apenas transmitir o conhecimento: "Não deve entender o educando como objeto do processo, aquele que apenas escuta que deve ser educado e que não tem conhecimento" (FREIRE, 1994, p. 60). A educação bancária ainda é muito recorrente no cenário educacional brasileiro tornando-se imprescindível um novo olhar, voltado para a compreensão da forma como o aluno aprende. A tecnologia, cada vez mais vem fomentando novos paradigmas de aprendizagem ao âmbito educacional.

Segundo Barreto (2003), a principal questão é como associar um aplicativo à educação, pois não se deve ter apenas uma visão técnica ou somente do deslumbramento e sim investir no uso pedagógico, sobre temas abordados em sala de aula, e reflexivo na formação dos alunos. Dentre os conteúdos de Química, Barnea e Dori (1999) mostraram que muitos estudantes sentem dificuldades em relacionar as fórmulas moleculares dos compostos com suas fórmulas estruturais em três dimensões 3D um assunto abstrato em química. Assim, os aplicativos educacionais são ferramentas facilitadoras para compreensão dos conteúdos sobre geometria molecular, pois os alunos desenvolvem habilidades para visualizar moléculas no espaço, bem como, a concepção das propriedades físicas e químicas, além do mais, aprendem a importância desses conteúdos nas diversas disciplinas de química (SILVEIRA, 2013).

As TIC's surgiram para alguns professores como uma linguagem a mais, como um recurso que pode ter várias utilidades pedagógicas, tais como: trazer textos, músicas, realizar uma pesquisa, utilizar um vídeo. Para os alunos é uma nova oportunidade de aprender. E ainda que sejam facilitadoras para novas interfaces pedagógicas, muitas escolas pró́bem ou não incentivam adequadamente o seu uso. Esse, portanto, é o grande paradigma das tecnologias de sala de aula, pois é muito comum o aluno não se abster de utilizar, por exemplo, seu aparelho 
celular, ainda que seja proibido seu uso em sala de aula.

Isomeria é um fenômeno no qual dois ou mais compostos diferentes apresentam a mesma fórmula molecular e diferentes fórmulas estruturais. O estereoisômeros são compostos pertencentes a um mesmo grupo funcional, com mesmo tipo de estrutura esqueletal (cadeia carbônica) e mesma posição de insaturação, grupo funcional, heteroátomo ou substituinte. A diferença entre os estereoisômeros está na configuração das moléculas, ou seja, na disposição espacial dos átomos que constituem as moléculas isômeras.

Os estereoisômeros podem ser divididos em dois grupos principais: diastereoisômeros (não são a imagem no espelho um do outro) e enantiômeros (são a imagem no espelho um do outro). Para compreendermos a estereoisomeria, é necessário primeiro entender a rotação que ocorre em torno das ligações simples entre carbonos.

Na molécula de etano, por exemplo, ocorre rotação em torno da ligação simples, fazendo que a molécula apresente duas conformações, estrela e eclipse (as infinitas conformações intermediárias denominam-se oblíquas). Quando dois átomos de carbono fazem uma ligação dupla, não é possível haver rotação entre eles. Qualquer tentativa de rotação entre os átomos de carbono ocasiona o rompimento da ligação.

\section{Diastereoisomeria cis-trans em compostos de cadeia acíclica}

Em um composto de cadeia acíclica (aberta), se os ligantes de cada átomo de carbono da dupla forem diferentes entre si e iguais aos ligantes do outro átomo de carbono, tem-se a formação de dois compostos, que são os diastereoisômeros cis e trans.
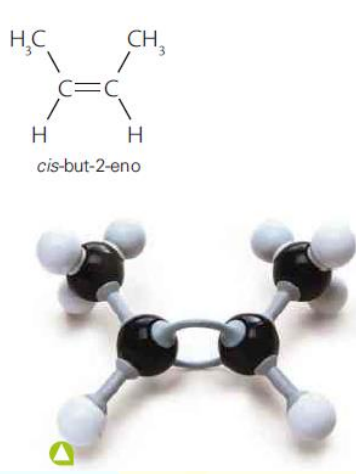

Figura 01: Isomeria geométrica (Cis e Trans) - Fonte: Reis (2016)

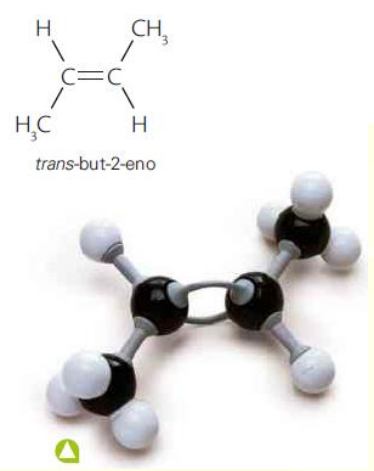

Observando que o isômero cis possui ligantes iguais em cada átomo de carbono da dupla em um mesmo plano e o isômero trans possui ligantes iguais em cada átomo de carbono da dupla em planos opostos.

\section{Observações:}

a) é necessário que os ligantes de cada átomo de carbono da dupla sejam diferentes entre si, pois, se forem iguais, não haverá isomeria. Considere, por exemplo, o propeno: 


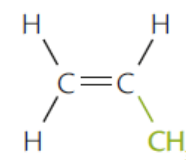

é igual a

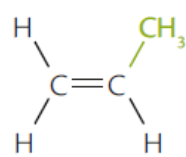

Figura 02: Isomeria geométrica do propeno (Cis e Trans) - Fonte: Reis (2016)

\section{Diastereoisomeria E-Z}

Os termos cis e trans podem se tornar ambíguos se forem aplicados a alcenos cujos átomos de carbono da dupla tenham, em conjunto, mais que dois ligantes diferentes. Considere, por exemplo, o 3-metilpent-2-eno:

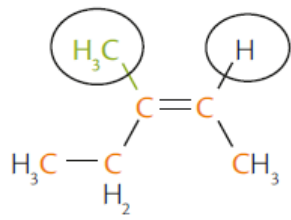

Figura 03: Isomeria geométrica do 3-metilpent-2-eno (E - Z) - Fonte: Reis (2016)

No sistema $\mathbf{E}-\mathbf{Z}$, a letra E vem da palavra alemão entgegen, opostos, e a letra Z, da palavra alemão zusammen, juntos. Note que os ligantes em destaque são os mais simples de cada carbono da dupla e, por estarem em um mesmo plano, esse seria o isômero cis. Essa ideia, no entanto, definição vista anteriormente, pois os ligantes iguais estão em planos opostos.

Para evitar esse tipo de impasse, nesses casos, o mais correto é usar o sistema de nomenclatura E-Z, proposto pelo químico orgânico inglês Christopher Kelk Ingold (18931970), pelo químico orgânico naturalizado suíço Vladimir Prelog (1906-1998) e por colaboradores.

No sistema E-Z, examinamos os dois grupos ligados a cada átomo de carbono da duplaligação e os colocamos em ordem de prioridade. Terá maior prioridade o ligante cujo átomo imediatamente ligado ao carbono da dupla tiver maior número atômico.

\section{METODOLOGIA}

Esta pesquisa foi desenvolvida pelo Instituto Internacional Despertando Vocações (IIDV) ligado ao Programa Internacional Despertando Vocações para Licenciaturas (PDVL).

\section{Caracterização do Campo da Pesquisa}

A pesquisa foi concretiza na escola parceira do PDVL, na Cidade da Região Metropolitana do Recife (RMR), no estado de Pernambuco. Os sujeitos foram 37 (trinta e sete) estudantes do $3^{\circ}$ ano do ensino médio.

\section{Instrumentos de Coleta}

Foram empregados como instrumentos de pesquisa questionário com os discentes, observação e registro da vivência do Ciclo da Experiência Kellyana - CEK, (KELLY, 1955). 
Com isso, utilizamos como base metodológica o ciclo da experiência Kellyana (CEK) o qual é fundamentado na Teoria dos Construtos Pessoais de George Kelly (1963).

\section{Aplicação do Ciclo da Experiência Kelly (CEK) - "APP - Isomère Z/E"}

- Antecipação: nesta etapa foi concretizada um diagnóstico dos dados prévios dos estudantes, onde eles foram examinados a identificar quais estruturas apresentam isomeria geométrica e como nomear as estruturas com (cis e trans) e $(E-Z)$.

\section{Nomenclatura 01: eteno}

Nomenclatura 02: 2,3-dicloro-but-2-eno

Nomenclatura 03: but-1-en-1-ol

Nomenclatura 04: 3-fluor-pent-3-en-2-ol

Nomenclatura 05: 2-bromo-hept-2-eno

Nomenclatura 06: hex-2-eno

- Na segunda etapa, chamada de Investimento, é esclarecido o conteúdo, onde foram citados alguns modelos para identificar e nomear os compostos orgânicos.

- A terceira etapa do CEK, chamada de Encontro, nesta ocasião os estudantes receberam as diretrizes do uso do APP - "Isomère Z/E” que está disponível no Play Store.

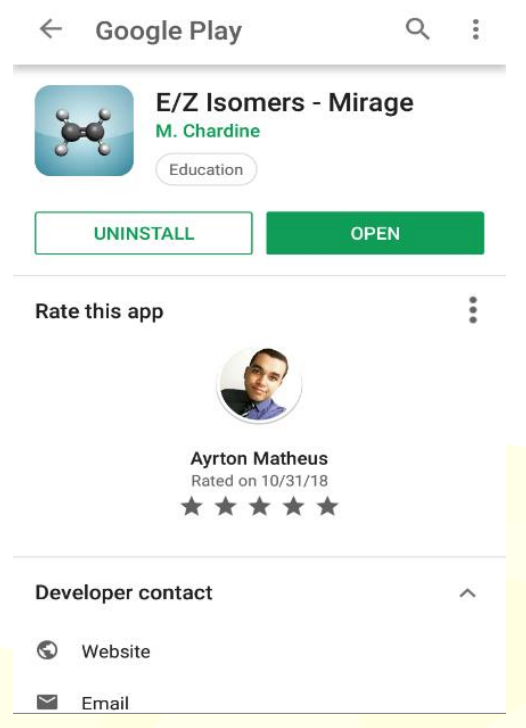

Figura 04: Interface do APP Isomère Z/E - Fonte: M. Chardine (2014)

- A quarta etapa, chamada de Confirmação ou Desconfirmação, é como os discentes são convidados a confirmar ou desconfirmar as suas ideias primitivas referente ao assunto de isomeria geométrica (estereoisomeria) respondendo os elementos para identificar as informações conceituais

- No encerramento desse ciclo, foi concretizado a quinta etapa, a chamada de Revisão Construtiva, nessa etapa os sujeitos são indagados a pensarem a respeito da temática. DESCRIÇÃO DO JOGO - “APP - Isomère Z/E”

Esta atividade com o uso da tecnologia "Isomère Z/E" tem o objetivo de identificar quais [108] 
estruturas apresentam isomeria geométrica e como nomear as estruturas com (cis e trans) e (E - Z). Este APP foi baixando na plataforma digital (Play Store) de autoria M. Chardine (2014), onde apresenta 10 (dez) cartas que QR-CODE para projetar as estruturas carbônicas como mostras as imagens abaixo. Utilizamos como orientação para construção deste jogo os estudos de Reis (2015).
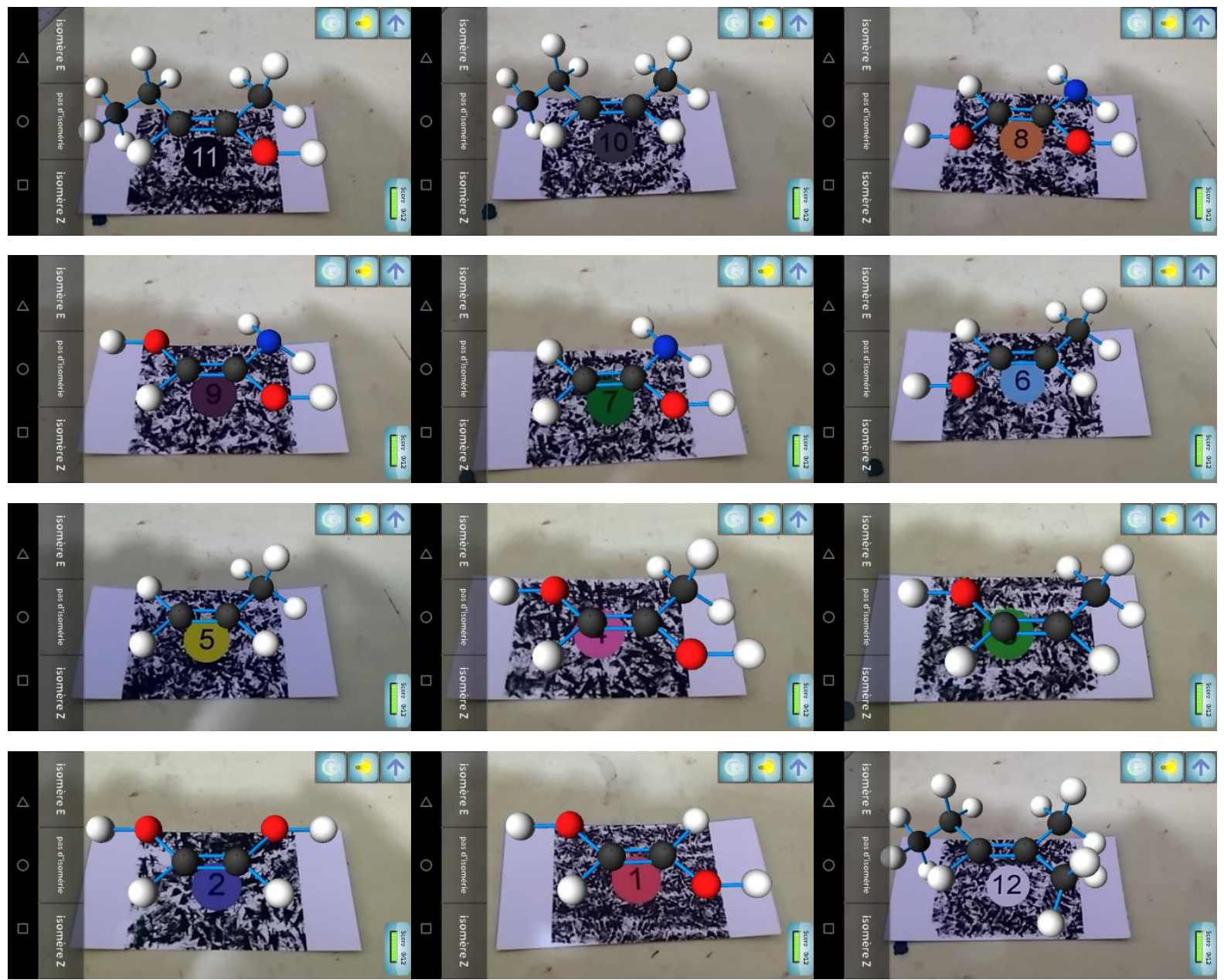

Figura 05: Cartas com QR-CODE do APP Isomère Z/E - Fonte: M. Chardine (2014)

\section{REGRAS}

Segue abaixo as orientações de formação de grupos por quantidade de alunos:

$\checkmark$ Após a divisão dos grupos, com 03 (três) integrante em cada grupo;

$\checkmark$ É necessário que todos os estudantes estejam com o APP instalado em seu smartphone para iniciar as atividades;

$\checkmark$ Todas os grupos receberão as 10 (dez) cartas com o QR-CODE do APP Isomère Z/E;

$\checkmark$ E cada equipe terão 40 (quarenta) segundos para classificarem as estruturas carbônicas como (Cis ou Trans) e (E ou Z), para cada acerto vale 10 (dez) pontos;

$\checkmark$ Em seguida, terão 120 (cento e vinte) segundos para nomear as estruturas carbônicas como (Cis ou Trans) e (E ou Z), para cada acerto vale 20 (vinte) pontos; 
$\checkmark$ Registrando os acertos e erros de cada estudante;

$\checkmark$ A conclusão dos dois momentos verifica-se qual(is) estudante(s) acertou mais as classificações e nomeação dos compostos orgânicos assim como (Cis ou Trans) e (E ou Z)

\section{RESULTADOS E DISCUSSÃO}

\section{Vivência do Ciclo da Experiência Kellyana (CEK) - "APP - Isomère Z/E"}

Nesta experiência do ciclo foram diagnósticados alguns pontos que favoreceram as ideias dos estudantes referente a isomérie geométrica (ou esterioisomeria). Abaixo segue detalhadamente as discussões da experiência:

$\mathrm{Na}$ Antecipação, inicia-se o CEK, onde os estudantes foram questionados sobre a construção e nomeação dos 06 (seis) compostos orgânicos onde tem que identificar que as estruturas apresentam isomeria geométrica, como mostra o gráfico 01.

\section{ANTECIPIÇÃO}

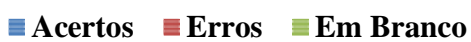

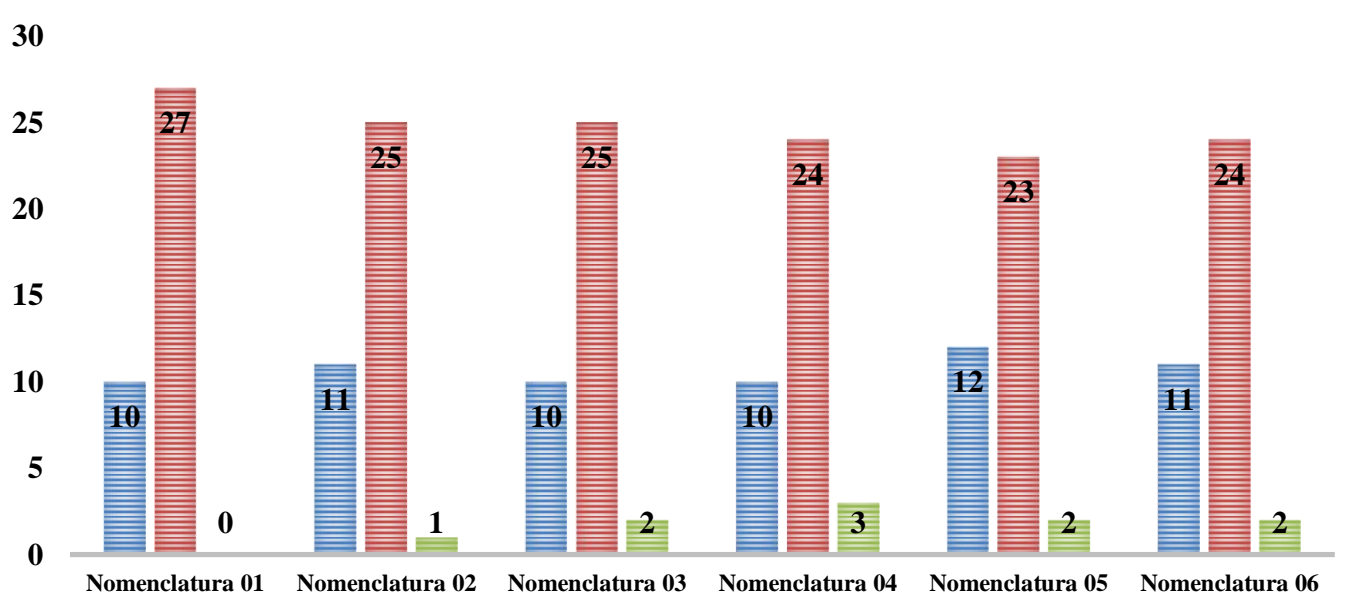

Gráfico 01: Quantidade de acertos e erros da antecipação - Fonte: Própria

Para verificar os acertos e erros, é necessário as orientações dos estudantes de Reis (2015), onde $71 \%$ dos estudantes obtiveram dificuldades para identificar e classificar as estruturas carbônicas com (Cis ou Trans) e (E ou Z).

No Investimento foi cogitado em cima dos números de dificuldades que foi apresenta no tópico acima, e foi detectado que os estudantes não conseguiram identificar as ligações duplas (carbono insaturado), e não visualizavam os ligantes, a partir disso conseguia verificar a classificação.

No Encontro foi necessário ser direcionado pelas regras do uso do APP. Esta fase teve em média 45 (quarenta e cinco) minutos. No período do uso do APP (encontro) os estudantes interagiram entre si, e apareceram bastante a interligação entre estudante-estudante, estudante- 
tecnologia e aprendizagem-tecnologia.
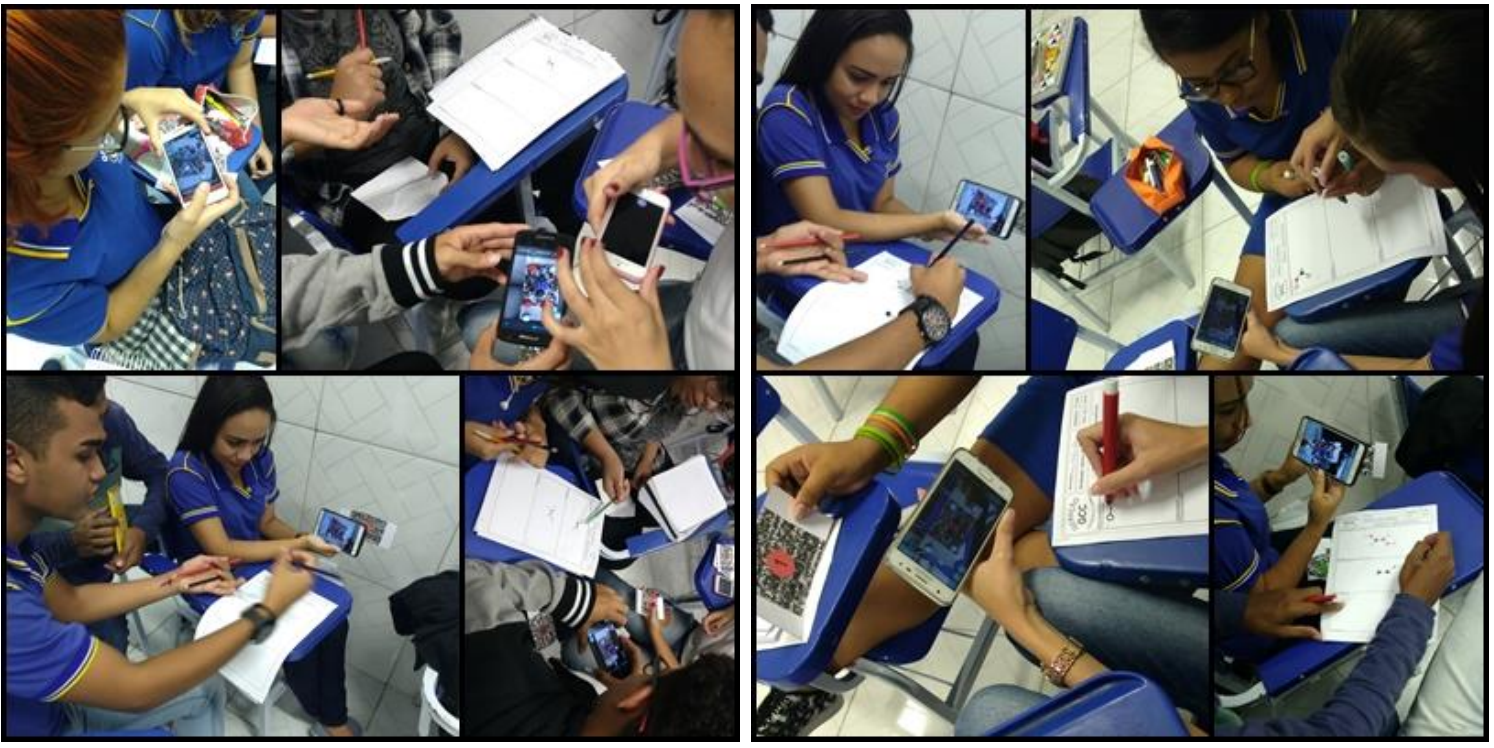

Figura 06: Vivência com o uso do APP - Isomère Z/E - Fonte: Própria

Na Confirmação ou Desconfirmação confere-se as opiniões dos alunos sobre os conceitos de isomeria geométrica (ou estereosiomeria), onde foi feitas as mesmas perguntas da primeira etapa, para confirmar ou desconfirmar as ideias iniciais, e detectar se o uso do APP apresentou algum benefícios para os estudantes nas aprendizagens de conceitos. No gráfico abaixo apresenta a quantidade de acertos e erros após a vivência com o uso do APP, e pode-se percebe que a quantidade de erros é equivalente a $16 \%$, onde houve uma redução de $52 \%$, e os de erros chegou a $84 \%$, mostrando-se assim que o uso de recurso didático em sala de aula, contribui para o processo de formação e construção dos conceitos químicos.

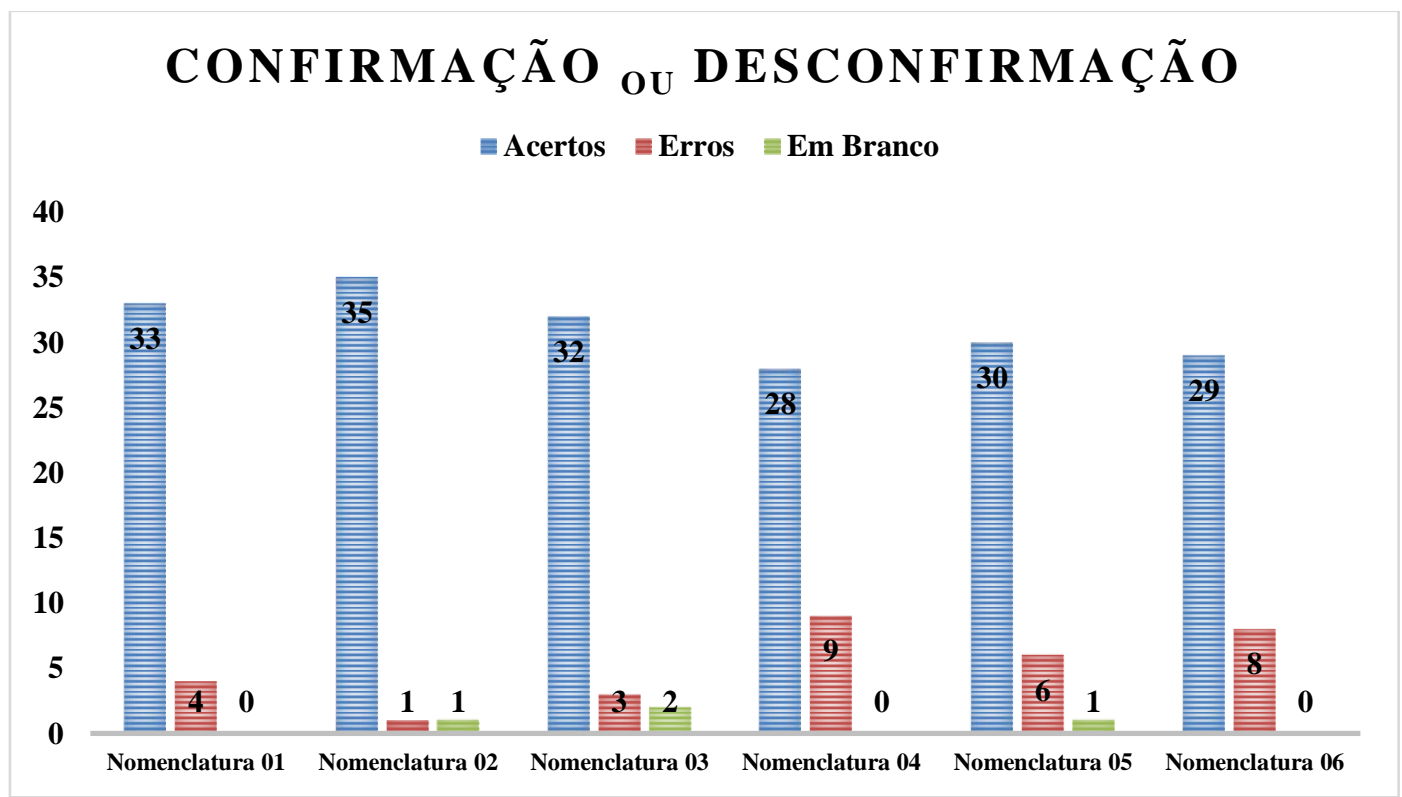

Gráfico 02: Quantidade de acertos e erros da confirmação ou desconfirmação - Fonte: Própria

Na Revisão Construtiva foi concentrizado uma conversa sobre a utilização de 
tecnologias no ensino de química, os benefícios e os malefícios do seu uso, verificamos alguns recortes desta vivência abaixo:

(i) Sobre o uso de tecnologia no ensino de química, qual(is) é(são) o(s) benefício(s) ou malefício(s)?

Sujeito 03: "benefício e ver os átomos fica mas fácil".

Sujeito 06: "o bom é que conseguemos entender as moléculas e ligações".

(ii) Comente o uso do APP (Isomère Z/E).

Sujeito 12: "esse aplicativo é bom que pode usar online".

Sujeito 11: "tem uma imagem ilustrativa muito boa".

\section{CONCLUSÕES}

Contudo, percebemos que, o conhecimento adquirido com o uso do APP (Isomère Z/E) apresentou grande contribuições para os estudantes, onde aprenderam de forma lúdica e interativa, dessa forma foi atribuída significados para o uso de APP em sala de aula, na qual se refere ao seu próprio processo de aprendizagem, estando esse processo fundamentado numa perspectiva mais ampla, que envolve antes, uma clareza epistemológica no que se refere à compreensão de como os sujeitos aprendem na interação com esses dispositivos e aplicativos, na relação com as especificidades da área do conhecimento (Química), para que dessa forma, possam desenvolver metodologias, práticas e processos de mediação pedagógica capazes de provocar mudanças significativas na forma de se ensinar e de aprender, considerando as especificidades desses dispositivos, bem como o contexto da mobilidade.

Nota-se que esta tecnologia usada na aula de Química no conteúdo de Isomeria Geométrica (ou Estereoisomeria) apresentará grande contribuições para o ensino, onde foi perceptível que os estudantes conseguiram diferenciar os tipos de isomerias (cis ou trans) e ( $Z$ ou E). O uso desta metodologia inovadora, busca essa nova apreciação para o ampliação das tecnologias nas aulas de química, podendo assim, fazer a diferença na aprendizagem de cada sujeito.

\section{REFERÊNCIAS}

BARBOSA A. F. (coord). Pesquisa sobre o uso das tecnologias de informação e comunicação nas escolas brasileiras: TIC Educação 2013. 2014.

BARNEA, N; DORI, Y.J. High school chemistry students perfornmance and gender diferences in a computerized molecular modeling learning inviroment.Journalof Science Educationand Technology v.8, n.4, p.257-271, 1999.

BARRETO, Raquel Goulart. Tecnologias educacionais e educação a distância: avaliando políticas e práticas. Rio de Janeiro: Quartet, 2003. 
BENTO, M.C.M., CAVALCANTE, R.S. Tecnologias Móveis em Educação: o uso do celular na sala de aula. ECCOM, v.4,n.7, jan./jun.,2013.

FREIRE, Paulo. Pedagogia da esperança: um reencontro com a pedagogia do oprimido. Rio de Janeiro: Paz e Terra, 1994.

KELLY, G. A. A theory of personality: the psychology of personal constructs. New York: W.W. Norton, 1963.

KELLY, G. A. The psychology of personal constructs. Vols. 1 e 2. New York: Norton, 1955.

LÉVY, P. Cibercultura. São Paulo: Editora 34, 2005.

MOURA, J. A. S.; C., A.; LAMOUNIER, E. J. A Realidade Virtual como uma ferramenta para o ensino da Geometria Molecular. Universidade Federal de Uberlândia. Disponível em http://www.lbd.dcc.ufmg.br/colecoes/wrva/2009/0012.pdf.

SANTORI, A. S. Uso das TICs Como Ferramentas de Ensino e Aprendizagem, Notas Para uma Prática Pedagógica Educomunicativa. Caso Florianópolis p. 135, 2014.

SARRAMONA, J. Factores e indicadores de calidad en la educación. Barcelona: Octaedro, 2004.

WOLTON, Dominique. É preciso salvar a comunicação. Tradução de Vanise Pereira Dresch. São Paulo: Paulus, 2006. 